\title{
Liposome-based immunostrip for the rapid detection of Salmonella
}

\author{
Ja-an Annie Ho • Shi-Chin Zeng • Wei-Hsiang Tseng • \\ Yong-Jen Lin $\cdot$ Chun-hsien Chen
}

Received: 31 October 2007 /Revised: 21 December 2007 / Accepted: 10 January 2008 / Published online: 14 February 2008

(C) Springer-Verlag 2008

\begin{abstract}
Salmonellae are ubiquitous human pathogens, which pose a danger to the elderly and children. Due to the increased number of outbreaks of human illness associated with the consumption of contaminated products in the USA and many other countries, there is an urgent need to develop rapid assays to detect common food-borne pathogens. This study demonstrates the feasibility of using a detectable label comprising methyl blue (MB), a visible dye, entrapped inside liposomes. Immunoliposomes tagged with anti-Salmonella common structural antigens (CSA) antibody encapsulating MB dye were prepared and used as the signal amplifier for the development of a field-portable colorimetric immunoassay to detect Salmonellae. Tapping mode atomic force microscopy (TMAFM), a scanning probe technique, was utilized to demonstrate the presence of anti-Salmonella antibody at the thus-prepared liposome. A plastic-backed nitrocellulose strip with two immobilized zones formed the basis of a sandwich assay. The first zone was the antigen capture zone (AC zone), used in a sandwich (noncompetitive) assay format; the other was the biotin capture zone (BC zone), used as a quality control index for the strip assay. During the capillary migration of the wicking reagent containing $80 \mu \mathrm{L}$ of immunoliposomes
\end{abstract}

Shi-Chin Zeng and Wei-Hsiang Tseng contributed equally to this publication.

J.-a. A. Ho $(\bowtie) \cdot$ S.-C. Zeng $\cdot$ W.-H. Tseng $\cdot$ Y.-J. Lin

Department of Chemistry, National Tsing Hua University,

101, Section 2, Kuang-Fu Road,

Hsinchu 30013, Taiwan

e-mail: jaho@mx.nthu.edu.tw

C.-h. Chen

Department of Chemistry, National Taiwan University,

Taipei 10617, Taiwan and $40 \mu \mathrm{L}$ of the test sample (heat-killed S. typhimurium), sample pathogens with surface-bound immunoliposomes were captured at the AC zone, while the unbound immunoliposomes continued to migrate and bind to the anti-biotin antibodies coated on the $\mathrm{BC}$ zone. The color density of the AC zone was directly proportional to the number of Salmonella typhimurium in the test sample. The detection limit of the current assay with heat-killed Salmonella typhimurium was 1,680 cells. The crossreactivity of the proposed immunoassay was also investigated, and pathogens including E. coli $\mathrm{O} 157: \mathrm{H} 7$ and Listeria genus specific caused no interference with the detection of Salmonella typhimurium.

Keywords Salmonella typhimurium · Point-of-care diagnostics · Lateral flow immunoassay · Pathogen detection

\section{Introduction}

Pathogens such as Salmonellae, Escherichia coli O157:H7, Campylobacter jejuni, Vibrio cholerae, parasites, and viruses are likely to contaminate fresh produce through raw or improperly composted manure, irrigation water containing untreated sewage, or contaminated wash water. The Centers for Disease Control and Prevention (CDC) estimates that 76 million cases of food-borne illnesses or food poisoning occur every year in the USA, which can amount to $\$ 35$ billion annually in medical costs and lost productivity [1].

Salmonellosis, a disease caused by Salmonellae, affects an estimated two million Americans each year and is common throughout the world. In 1994, an outbreak of salmonellosis that affected an estimated 224,000 persons in the USA was attributed to a large supply of contaminated 
ice cream [1-4]. Salmonella species are Gram-negative, flagellated, facultatively anaerobic bacilli possessing three major antigens: $\mathrm{H}$, or flagellar antigen; $\mathrm{O}$, or somatic antigen; and Vi antigen (possessed by only a few serotypes) $[5,6]$. Pathogenic Salmonellae ingested in food survive passage through the gastric acid barrier and invade the mucosa of the small and large intestine to produce toxins.

Salmonellae consist of a range of very closely related bacteria, each with its own unique impact on the human body. The three main serotypes of Salmonella enterica are Typhimurium, Enteritidis, and Typhi. Of these, S. typhimurium is the most common cause of food poisoning by Salmonella species in recent years. In the clinical laboratory, Salmonellae are usually grown isolated on brilliant green sulfa agar, bismuth sulfite agar, XLT4 agar, double modified lysine iron agar, or XLD agar, or DCA [7, 8]. They form moist colonies about 2 to $3 \mathrm{~mm}$ in diameter and are incapable of fermenting lactose and producing $\mathrm{H}_{2} \mathrm{~S}$.

Identification of the widespread outbreaks of food illness is a considerable challenge for public health officials. The most difficult outbreaks to detect are those that span a large geographical area. In an effort to make outbreaks easier to pinpoint, more-rapid assays of investigation are continuously being developed. New technologies such as PCR [9-16], nucleic acid-based assays $[14,15]$, or DNA fingerprinting $[16,17]$ make it easier for local officials to compare strains of pathogens found in cases across the country. Another type of method, antibody-based assays [18-33], has also been reported to apply in the detection of Salmonella to simplify the time-consuming, labor-intensive conventional culture methods (usually requiring more than 5 days).

Liposomes [34-36] have been used intensively in our laboratory for encapsulating various signal-generating molecules, such as fluorophores, DNA, and photoproteins, for the development of immunodetection systems [37-44]. Immunodetection techniques, which utilize immunological reactions to measure the presence of a target substance, offer sensitivity, speed, and simplicity of operation, providing potential solutions to the need for more-rapid identification of pathogens.

Despite notable advances in food-processing industries, food-borne illnesses continue to be a significant growing public health problem. In laboratory diagnosis, most microbiological assays rely on a single phenotype to selectively isolate a pathogen, which is a slow process. Therefore, as part of our project on the development of rapid assays for the detection of multi-pathogenic bacteria such as Salmonellae and E. coli O157:H7, we present here a simple and rapid immunostrip assay for Salmonella detection, which has potential as a rapid and inexpensive point-of-care diagnostic assay.

\section{Materials and methods}

Reagents and materials

All inorganic chemicals and organic solvents used were reagent grade or better. Dipalmitoylphosphatidylcholine (DPPC), dipalmitoylphosphatidylglycerol (DPPG), and dipalmitoylphosphoethanolamine (DPPE) were purchased from Avanti Polar Lipids (Alabaster, AL, USA). $\mathrm{N}-(\kappa-$ Maleimidoundecanoyloxy)sulfosuccinimide ester (sulfoKMUS), $N$-ethylmaleimide, hydroxylamine hydrochloride, and succinimidyl-S-acetylthioacetate (SATA) were purchased from Pierce Chemicals Co. (Rockford, IL, USA). Methyl blue $\left(\mathrm{C}_{37} \mathrm{H}_{27} \mathrm{~N}_{3} \mathrm{Na}_{2} \mathrm{O}_{9} \mathrm{~S}_{3}\right)$ was purchased from Waldeck GmbH \& Co. KG Division Chroma (Muenster, Germany). Biotin-X-DHPE ( $N$-((6-(biotinoyl)amino)hexanoyl)-1,2-dihexadecanoyl-sn-glycero-3-phosphoethanolamine, triethylammonium salt) was purchased from Molecular Probes (Eugene, OR, USA). Affinity-purified polyclonal antibody (goat anti-Salmonella, CSA-1), heatkilled Salmonella typhimurium, E. coli O157:H7, and Listeria genus specific were purchased from KirkegaardPerry Laboratories, Inc. (Gaithersburg, MO, USA). Nitrocellulose membranes were purchased from Millipore (Bedford, MA, USA). All other chemicals were purchased from Sigma Chemical Co. (St. Louis, MO, USA).

\section{Preparation of dye-encapsulated liposomes}

Liposomes were prepared by a reversed-phase evaporation [45-47] method described previously [40], involving a water-in-oil emulsion. Briefly, the lipid mixture consisted of DPPC, cholesterol, DPPG, DPPE, and Biotin-X-DHPE in a molar ratio of 5:5:0.5:0.25:0.005. This was first dissolved in a solvent mixture consisting of chloroform, isopropyl ether, and methanol (4:4:2), followed by 1-min sonication at $45{ }^{\circ} \mathrm{C}$ under nitrogen. One milliliter of $30 \mathrm{mM}$ methyl blue was then added to the lipid mixture. After sonication of the solution for a further $5 \mathrm{~min}$ with occasional swirling, the organic solvent was removed by evaporating at $45{ }^{\circ} \mathrm{C}$, leaving a dark blue, gel-like suspension of liposomes. An additional $1 \mathrm{~mL}$ of methyl blue was added, followed by another $5 \mathrm{~min}$ of sonication at $45{ }^{\circ} \mathrm{C}$. The liposomes preparation was incubated in a $45{ }^{\circ} \mathrm{C}$ water bath for $30 \mathrm{~min}$ before passing through 2 - and $0.4-\mu \mathrm{m}$ polycarbonate filters to produce a homogenous suspension of uniform size. Any unencapsulated dye or trace of organic solvent was removed from the liposomes preparation by gel filtering on a $1.5 \times 25-\mathrm{cm}$ Sephadex G-50-150 column at room temperature, followed by dialysis (MWCO, $12-14 \mathrm{kDa}$ ) at $4{ }^{\circ} \mathrm{C}$ in the dark. 


\section{Derivatization of liposomes with sulfo-KMUS}

One milligram of sulfo-KMUS was first dissolved in $10 \mu \mathrm{L}$ of dimethyl sulfoxide (DMSO) solution and added to the dialyzed liposome preparation. The mixture was allowed to react at room temperature for $2.5 \mathrm{~h}$. The reaction was stopped by reacting with Tris- $\mathrm{HCl}(\mathrm{pH} 7.8)$ for $15 \mathrm{~min}$ at room temperature on the shaker, followed by dialysis (MWCO, 12-14 kDa) against $10 \mathrm{mM}$ HEPES buffer, $\mathrm{pH} 7.5$, containing $\mathrm{NaCl}$ and sucrose at $4{ }^{\circ} \mathrm{C}$ in the dark.

Preparation of SATA-modified antibodies

Two milligrams of goat anti-Salmonella antibody $(\mathrm{Ab})$ were dissolved in $0.1 \mathrm{~mL}$ of $10 \mathrm{mM}$ phosphate-buffered saline (PBS) at $\mathrm{pH} 7.2$. A 1.0-mg sample of SATA in DMSO $(10 \mu \mathrm{L})$ was added to the Ab solution. The mixture was then allowed to react on a shaker for $30 \mathrm{~min}$ at room temperature, followed by dialysis (MWCO, 6-8 $\mathrm{kDa}$ ) against $10 \mathrm{mM}$ PBS ( $\mathrm{pH}$ 7.2) containing ethylenediaminetetraacetic acid (EDTA) at $4{ }^{\circ} \mathrm{C}$ for $3.5 \mathrm{~h}$. Concurrently, the acetylthioacetyl-antibody was deprotected by adding hydroxylamine hydrochloride $(100 \mu \mathrm{mol})$ to obtain free sulfhydryl groups. Subsequently, the thiolated $\mathrm{Ab}$ was purified by gel filtration on Sephadex G-25. Fractions containing sulfhydryl (SH)-derivatized protein were collected by measurement of the absorbance at $280 \mathrm{~nm}$.

Conjugation of maleimide-derivatized liposomes with SHcontaining antibody

The coupling of thiolated $\mathrm{Ab}$ to maleimide-derivated liposomes was achieved by incubating overnight at $4{ }^{\circ} \mathrm{C}$. Unreacted sulfhydryl groups on the antibody and the unreacted sulfo-succinimidyl groups on the sulfo-KMUS were subsequently capped with $N$-ethylmaleimide and Tris base. The antibody-tagged liposomes were separated from unreacted SH-derivatized antibody on a Sepharose CL-4B column equilibrated with Tris-buffered saline (TBS) (pH 7.0) containing sucrose. The desired fraction of liposomes was collected, followed by dialysis at $4{ }^{\circ} \mathrm{C}$ in the dark for improved stability.

Stability study and characterization of liposomes

The intactness of liposomes means the maintenance of their integrity, which can be determined by measuring absorbance from $\mathrm{MB}$ before and after lysis. According to our previous studies, almost instantaneous and total lysis of liposomes was observed at room temperature when a solution of $50 \mathrm{mM} n$-octyl $\beta$-D-glucopyranoside (OG) was added [39]. The diameter of the liposomes was measured with a Malvern nano-S90 particle size analyzer (Malvern, Worcestershire, UK) using the manufacturer's method. In addition, tapping mode atomic force microscopy (TMAFM), a scanning probe technique that exerts only minimal force on soft materials, was utilized to demonstrate the presence of anti-Salmonella antibody at the thusprepared liposome. TMAFM measurements were carried out with a NanoScope IIIa controller (Veeco Metrology Group, Santa Barbara, CA). Images were acquired using a 10- $\mu \mathrm{m}$ scanner and monolithic silicon cantilevers (NCHR, NanoWorld, Switzerland) whose force constant and the tip curvature were nominally $42 \mathrm{nN} \mathrm{m}^{-1}$ and $<10 \mathrm{~nm}$, respectively. Samples for TMAFM were prepared by placing a drop of liposome solution on freshly cleaved mica. To remove the excess solution and physisorbed lipid, the films on mica were rinsed with water and then dried by a stream of $\mathrm{N}_{2}(\mathrm{~g})$. The microscope was housed in a Plexiglas chamber where dry $\mathrm{N}_{2}$ was purged throughout the experiments and the humidity was kept lower than $2 \%$.

\section{Preparation of test strips and assay procedures}

Immobilization of anti-Salmonella antibodies and antibiotin antibodies on the plastic-backed nitrocellulose membrane was done by manual pipetting. Affinity-purified polyclonal antibody to the Salmonella CSA was isolated from a serum pool of goats immunized with different serotypes of Salmonella. This antibody is broadly reactive to Salmonella and recognizes most Salmonella serotypes. The membrane was first cut into $10 \times 8.8-\mathrm{cm}$ sheets, followed by dot-blotting $2 \mu \mathrm{L}$ of anti-Salmonella antibody solution at a concentration of $2 \mathrm{mg} \mathrm{mL}^{-1}$ or $4 \mathrm{mg} \mathrm{mL}^{-1}$ and $1 \mu \mathrm{L}$ of anti-biotin antibody $\left(1 \mathrm{mg} \mathrm{mL}^{-1}\right)$, leading to a final amount of $4 \mu \mathrm{g}$ or $8 \mu \mathrm{g}$ of anti-Salmonella antibody and $1 \mu \mathrm{g}$ of anti-biotin antibody per strip. The antibody-coated dots were allowed to air-dry in the hood for $5 \mathrm{~min}$ and further dried under vacuum (10 psi) at room temperature for $1 \mathrm{~h}$. The coated nitrocellulose sheet was immersed in a blocking solution consisting of $0.5 \%$ poly (vinylpyrrolidone) and $0.03 \%$ casein in TBS at $\mathrm{pH} 7.5$ for $1 \mathrm{~h}$ on a rotating shaker, followed by drying under vacuum (10 psi) at room temperature for at least $6 \mathrm{~h}$. The prepared sheet was then cut into $0.5 \times 8.8-\mathrm{cm}$ strips using a paper cutter, producing strips with the antigen capture (AC) zone $1.5 \mathrm{~cm}$ and biotin capture (BC) zone $3.5 \mathrm{~cm}$ above the bottom of the strip. The prepared strips were stored at $4{ }^{\circ} \mathrm{C}$ until use.

The format for the proposed immunostrip assay consists of immunoliposomes solution, test sample, and nitrocellulose test strips with immobilized anti-Salmonella and anti- 
biotin antibodies. The assay was performed by dispensing $40 \mu \mathrm{L}$ of the sample pathogenic organism in PBS and $80 \mu \mathrm{L}$ of an immunoliposomes solution into a $1 \times 7.5-\mathrm{cm}$ glass test tube with gentle mixing for $30 \mathrm{~min}$. A test strip was then inserted into the test tube, and the chromatographic process was begun. After the solution front reached the upper end of the test strip, it was removed and air-dried. The color intensity of each zone on the test strip was estimated visually or quantified by using a scanning reflectance photometer (KGW Enterprises, Inc., Elkart, IN, USA)

\section{Selectivity of immunoliposomes}

The evaluation of the cross-reactivity of immunoliposomes with the target Salmonella typhimurium and negative controls such as E. coli. O157:H7 and Listeria genus specific was then conducted. The anti-Salmonella antibodycoated test strips were inserted into the test tubes that contained immunoliposomes and the target antigen or negative control pathogenic organisms. The color intensity of each zone on the test strips was estimated visually or quantified by scanning densitometry.

\section{Safety consideration}

Salmonella typhimurium is a harmful bacterium that should be handled with care. Heat-killed S. typhimurium, other pathogenic organisms, and organic solvents used in the modification and production of conjugated liposomes and in the performance of the assay were handled in either a laminar flow hood or chemical hood with surgical gloves. All S. typhimurium or other harmful pathogen-contaminated labwares were autoclaved before being discarded.

\section{Results and discussion}

Characteristics and stability of MB-encapsulated multivalent immunoliposomes

A multistep conjugation procedure for the preparation of MB-encapsulated, anti-Salmonella antibody-tagged liposomes (immunoliposomes) was demonstrated. Methyl blue, also known as cotton blue or helvetia blue, is a chemical compound commonly used as a stain in histology. In the current study, MB was chosen as the liposomal encapsulant due to its high water solubility. Sulfo-KMUS is a sulfhydryl-reactive and amine-reactive heterobifunctional cross-linker that conjugates thiolated immunoglobin $G$ $(\mathrm{IgG})$ and the primary amine group of DPPE on the liposome bilayer. The maleimide group of sulfo-KMUS is highly specific for coupling to sulfhydryl-containing molecules, thus directing the conjugation to the second molecules. The resulting biofunctionalized liposomes were proven to be more-stable complexes ( $>15$ weeks) using TMAFM.

Extrusion of the liposome preparations through polycarbonate filters was helpful for obtaining a homogeneous size of the liposomes, resulting in an even capillary migration on the test strips. Liposomes passed 20 times through a 0.4$\mu \mathrm{m}$ polycarbonate filter had a mean diameter of $236 \mathrm{~nm}$. The 236-nm liposomes were used in all subsequent experiments. The characteristics of liposomes are described as followed. With liposomes of 236-nm diameter it is possible to calculate that the average volume of a single liposome is $6.88 \times 10^{-12} \mu \mathrm{L}$ and the volume entrapped (assuming a bilayer thickness of $4 \mathrm{~nm}$ ) is $6.21 \times 10^{-12} \mu \mathrm{L}$. Assuming the MB dye concentration inside the liposomes was equal to the original $\mathrm{MB}$ dye solution used, and comparing the absorbance of lysed liposomes to that of standard MB solutions, it is possible to calculate that there were about $3.56 \times 10^{12}$ liposomes per $\mathrm{mL}$ and that each liposome contained ca. $1.33 \times 10^{5}$ molecules of dye. If the average surface area of the DPPC molecules is $71 \AA^{2}$, and that of cholesterol is $19 \AA^{2}$ [48], it is estimated that ca. 4,800 molecules of anti-Salmonella CSA antibody were on the outer surface of each liposome, given that $2.5 \mathrm{~mole} \%$ of sulfo-KMUS-derivatized liposomal DPPE successfully reacted with SH-derivatized IgG. Although it is likely that the high-protein-loaded particles would cause aggregation of antigens with changes of their flow properties, this was not observed in the current study.

The presence of antibody on the outer surface of liposome was confirmed by TMAFM. A literature report [49] showed that the adhesion of liposome on mica led to lipid bilayers where the phosphatidyl group adsorbed on the hydrophilic mica surface and the hydrophobic aliphatic chain drove the formation of the second layer in the hydrophilic aqueous environment. The left-hand image of Fig. 1 shows that, without incorporating Salmonella antibody, the morphology of the lipid film was smooth. The difference in height between terraces was ca. $5.5 \mathrm{~nm}$, thinner than two times the fully extended length of DPPC (ca. $3.4 \mathrm{~nm}$ ) [50] and in a good agreement with literature reports [51-53]. The right-hand of Fig. 1 is typical for films prepared from liposome with Salmonella antibody. The film exhibited protrusions of $1.9 \pm 0.5 \mathrm{~nm}$ in height, similar to the $3.0 \pm 1.0 \mathrm{~nm}$ found in a recent AFM study [54]. The diameters of the protrusions are $44 \pm 9 \mathrm{~nm}$. It is quite common in AFM images for the lateral dimensions of isolated objects to appear a lot larger than expected because of the finite size of the tip curvature. The protrusions were associated with the antibody because such protrusions did 

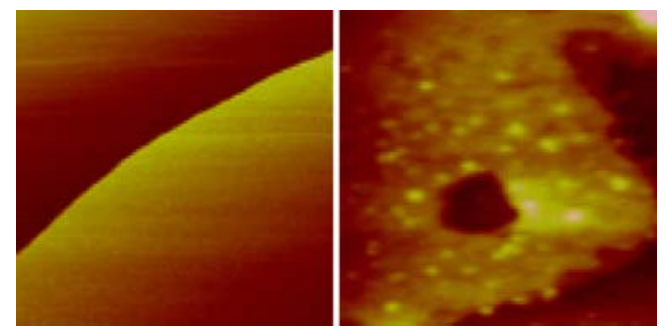

Fig. 1 TMAFM images revealing morphological features of lipid films adhered on mica. The left-hand and right-hand images were obtained, respectively, from liposomes without and tagged with Salmonella antibody. The contrast in the left-hand image indicates a height difference of ca. $5.5 \mathrm{~nm}$ between lipid bilayers (lower right) and mica substrate (upper left). The right-hand image exhibits protrusions of an apparent height of $1.9 \mathrm{~nm}$ above the bilayers, suggesting the intact nature of the antibody at the liposome. Image size $650 \times 650 \mathrm{~nm}$

not present in plain liposome. The TMAFM results confirm that the proposed multistep conjugation strategy can be used as the platform conjugation procedure for the preparation of antibody-tagged liposomes (immunoliposomes).

\section{Assay performance}

The assay involves an immobilized-antibody zone (antigen capture zone, AC zone) in the membrane strip that is exposed to the target antigen, Salmonella typhimurium, in a sample solution (Fig. 2). The multivalent immunoliposomes subsequently bind to the bound antigen in the $\mathrm{AC}$ zone, while free, unbound immunolipsomes continue to migrate to the biotin capture zone (BC zone). Thus the intensity of

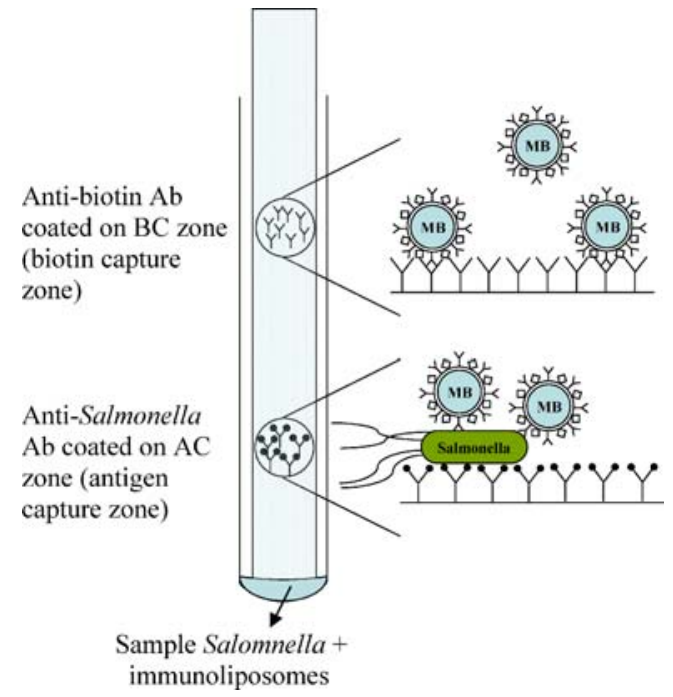

Fig. 2 Sandwich binding of sample Salmonella between the immunoliposomes and anti-Salmonella antibodies immobilized in the $\mathrm{AC}$ zone (drawing is not to scale)

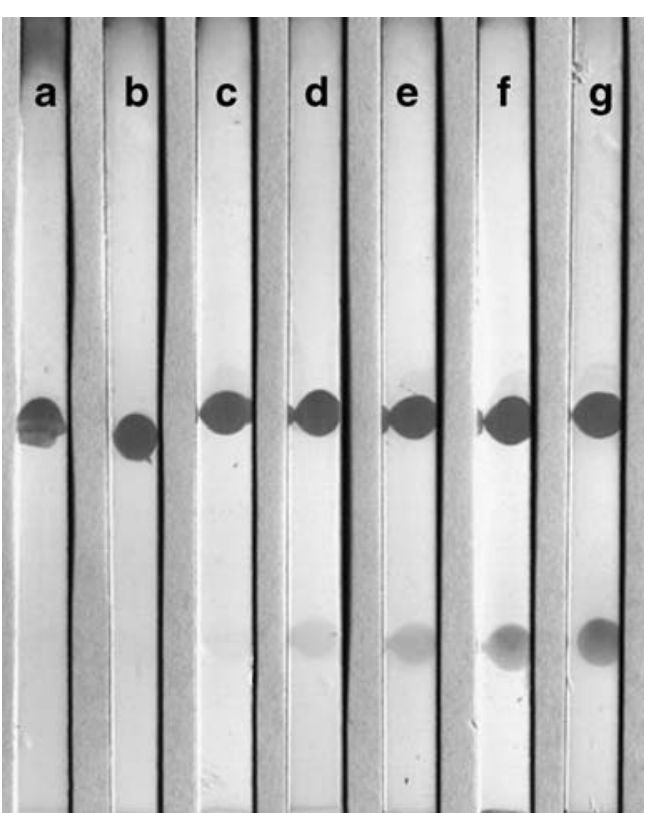

Fig. 3 Scanned image of the assay performed with different concentrations of heat-killed $S$. typhimurium. a contains no $S$. typhimurium, b $2 \times 10^{4}$ cells, c $2 \times 10^{5}$ cells, d $1 \times 10^{6}$ cells, e $2 \times$ $10^{6}$ cells, f $1 \times 10^{7}$ cells, g $2 \times 10^{7}$ cells

the blue color exhibited by the bound immunoliposomes on the AC zone is directly proportional to S. typhimurium present in the sample, and the color exhibited on the $\mathrm{BC}$ zone serves as a QC index for the test trips, as shown in Fig. 3. Since MB is a visible dye, the color intensity may be measured semiquantitatively by visual examination. However the use of a QuadScan reflectance photometer (KGW Enterprises, Inc., Elkhart, IN), which is equipped with a high-intensity incandescent lamp to illuminate specific zones to give a reflectance value, can provide more-

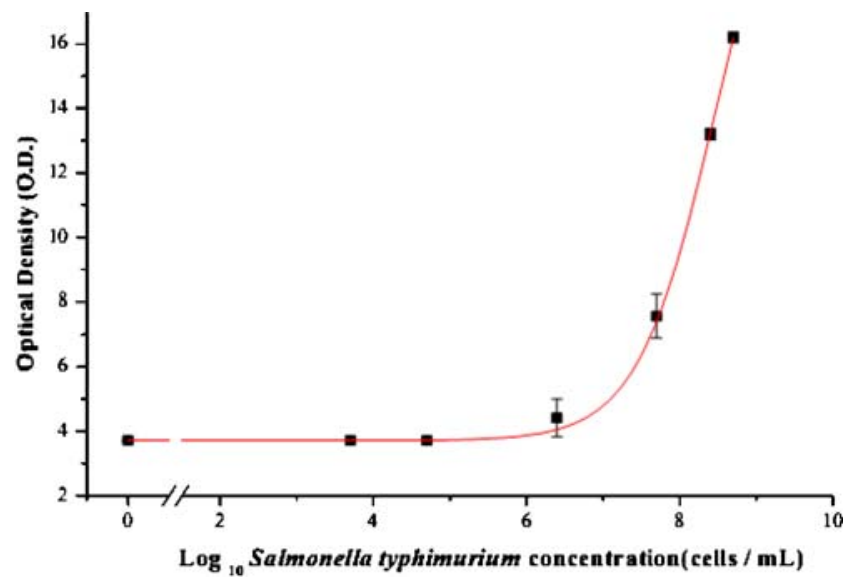

Fig. 4 Dose-response curve for the detection of heat-killed $S$. typhimurium. Each point represents the mean of three measurements; error bars represent $\pm 1 \mathrm{SD}$ (the datum point at zero represents signals from blank) 


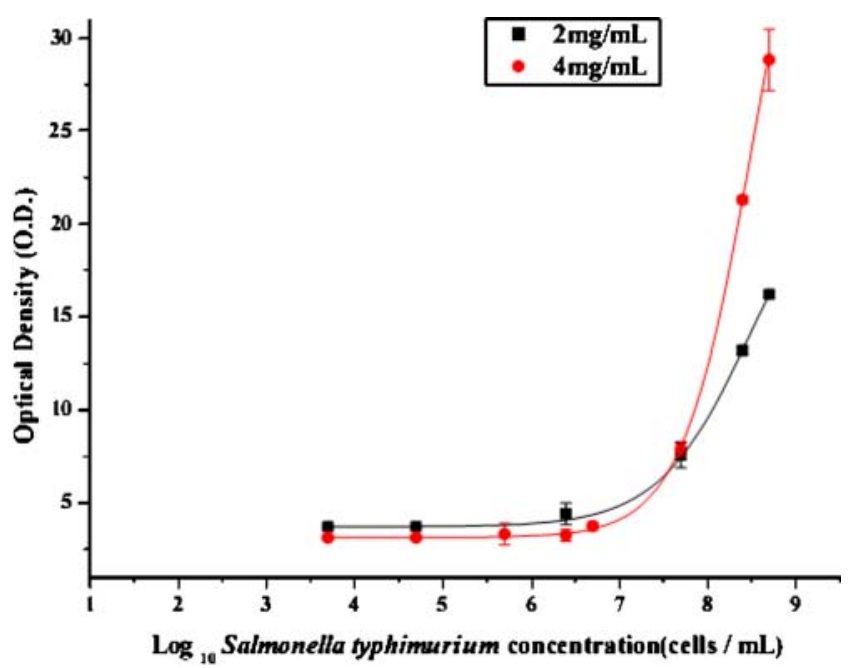

Fig. 5 Effects on the assay performance of antibody concentration immobilized on the nitrocellulose membrane (- $2 \mathrm{mg} \mathrm{mL} \mathrm{mL}^{-1}$, $4 \mathrm{mg} \mathrm{mL} L^{-1}$ )

accurate quantitation results obtained with various concentrations of S. typhimurium, as shown in Fig. 4. According to the International Union of Pure and Applied Chemistry (IUPAC), the operational definition of detection limit in this study is calculated at the concentration corresponding to a signal three times the standard deviation (SD) below the mean for a calibrator that is free of Salmonella. Therefore the very sensitive limit of detection (LOD) estimated at 3 SD was determined, namely 1,680 cells for heat-killed $S$. typhimurium with $99.7 \%$ confidence. The effect of immobilized antibody concentration on the assay performance was also investigated. As seen in Fig. 5, strips immobilized with $2 \mathrm{mg} \mathrm{mL}^{-1}$ of antibody showed a wider dynamic detection range for $S$. typhimurium. To evaluate the specificity of the assay, S. typhimurium and negative controls at $10^{7}$ to $10^{8}$ cells $\mathrm{mL}^{-1}$ were tested. As shown in Fig. 6, the assays did not show any significant crossreactivity to the nonspecific pathogenic organisms (negative controls).

The detection limits of other immunobiosensing devices reported previously for Salmonella spp. are around $10^{5}$ cells $\mathrm{mL}^{-1}$ using renewable amperometric immunoassay (assay time $90 \mathrm{~min}$ ) [27] and $10^{2}$ cells $\mathrm{mL}^{-1}$ using quartz crystal microbalance (QCM) [28] with simultaneous measurements of resonant frequency and motional resistance. It was also reported that $28 \mathrm{~h}$ was required to perform a dot blot immunoassay [32]. The immunostrip assay proposed here, however, has the advantages of lower cost, simplicity, and speed over other existing assay systems. The proposed assay does not need sophisticated instruments and is a potential alternative method for field screening of contaminated food samples.

\section{Conclusions}

Conventional methods for detection of Salmonella typhimurium is often labor-intensive, time-consuming, and costly. Unlike conventional ELISAs, our proposed immunostrip assay requires no enrichment, repetitive washing, or incubation steps and can be completed in $30 \mathrm{~min}$. Results obtained by TMAFM confirmed that the proposed multistep conjugation strategy can be successfully used as the platform conjugation procedure for the preparation of antibody-tagged liposomes. The methyl blue dye-entrapped, anti-Salmonella antibody-tagged immunoliposomes were successfully demonstrated to be useful in a sandwich immunoassay, which holds promise as a simple, rapid, and inexpensive quantitative assay for screening food samples for $S$. typhimurium with densitometry. Future

Fig. 6 Specificity of immunoliposomes to Salmonella: scanned image of the assay performed with a $E$. coli $\mathrm{O} 157: \mathrm{H} 7(6 \times$ $10^{7}$ cells), b Listeria genus specific $\left(4 \times 10^{7}\right.$ cells $)$, c the heat-killed S. typhimurium (4× $10^{7}$ cells)

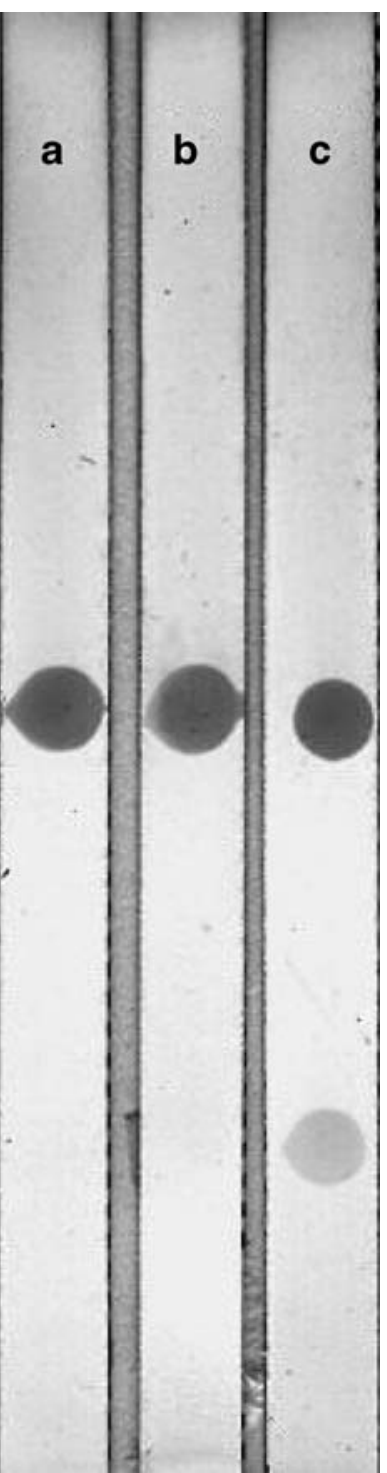


studies will focus on the development of the multianalyte immunodetecting system for $E$. coli $\mathrm{O} 157: \mathrm{H} 7$ and different Salmonella serotypes.

Acknowledgement This work was supported by the National Science Council in Taiwan, ROC, under grants NSC 95-2113-M007-040-MY3, and NSC 95-2113-M-002-036-MY3.

\section{References}

1. Voetsch AC, Van Gilder TJ, Angulo FJ, Farley MM, Shallow S, Marcus R, Cieslak PR, Deneen VC, Tauxe RV (2004) Clin Infect Dis 38:S127-134

2. Adak GK, Long SM, O'Brien SJ (2002) Gut 51(6):832-841

3. Chopra AK, Peterson JW, Chary P, Prasad R (1994) Microb Pathogen 16(2):85-98

4. Lee WC, Lee MJ, Kim JS, Park SY (2001) J Food Prot 64 (6):899-902

5. Popoff Y (2001) Antigenic formulas of the Salmonella serovars, 8th revision. WHO Collaborating Centre for Reference and Research on Salmonella, Institute Pasteur, Paris

6. Ekdahl K, de Jong B, Wollin R, Andersson Y (2005) Clin Microbiol Infect 11(2):138-144

7. Andrew WH, Hammack, TS (2003) Salmonella, Chap 5, Rev April. In: FDA bacteriological analytical manual, 8th edn, Rev A. AOAC International, Gaithersburg

8. USDA, Food Safety Inpection Service (2002) Isolation and identification of Salmonella from meat, poultry and egg products, MLG 4.02 rev. USDA-FSIS Microbiology Laboratory Guidebook, 3rd edn. US Department of Agriculture, Food Safety Inspection Service, Washington, DC

9. Bennett AR, Greenwood D, Tennant C, Banks JG, Betts RP (1998) Lett Appl Microbiol 26(6):437-441

10. Nam HM, Srinivasan V, Gillespie BE, Murinda SM, Oliver SP (2005) Int J Food Microbiol 102(2):161-171

11. Guo X, Chen J, Beuchat LR, Brackett RE (2000) Appl Environ Microbiol 66(12):5248-5252

12. Hong Y, Berrang ME, Liu T, Hofacre CL, Sanchez S, Wang L, Maurer JJ (2003) Appl Environ Microbiol 69(6):3492-3499

13. Daum LT, Barnes WJ, McAvin JC, Neidert MS, Cooper LA, Huff WB, Gaul L, Riggins WS, Morris S, Salmen A, Lohman KL (2002) J Clin Microbiol 40(8):3050-3052

14. Namimatsu T, Tsuna M, Imai $Y$, Futo $S$, Mitsuse $S$, Sakano T, Sato S (2000) J Vet Med Sci 62(6):615-619

15. Alvarez J, Porwollik S, Laconcha I, Gisakis V, Vivanco AB, Gonzalez I, Echenagusia S, Zabala N, Blackmer F, McClelland M, Rementeria A, Garaizar J (2003) Appl Environ Microbiol 69 (12):7531-7534

16. Rankin SC, Aceto H, Cassidy J, Holt J, Young S, Love B, Tewari D, Munro DS, Benson CE (2002) J Clin Microbiol 40(12):46794684

17. Suh DK, Song JC (2006) J Vet Sci 7(1):37-41

18. Valdivieso-Garcia A, Riche E, Abubakar O, Waddell TE, Brooks BW (2001) J Food Prot 64(8):1166-1171

19. Valdivieso-Garcia A, Desruisseau A, Riche E, Fukuda S, Tatsumi H (2003) J Food Prot 66(11):1996-2004
20. Fukuda S, Tatsumi H, Igimi S, Yamamoto S (2005) Lett Appl Microbiol 41(5):379-384

21. Wang H, Blais BW, Brooks BW, Yamazaki H (1996) Int J Food Microbiol 29(1):31-40

22. Taitt CR, Shubin YS, Angel R, Ligler FS (2004) Appl Environ Microbiol 70(1):152-158

23. Namimatsu T, Tsuna M, Imai Y, Futo S, Mitsuse S, Sakano T, Sato S (2000) J Vet Med Sci 62(6):615-619

24. Favrin SJ, Jassim SA, Griffiths MW (2001) Appl Environ Microbiol 67(1):217-224

25. McDonough PL, Jacobson RH, Timoney JF, Mutalib A, Kradel DC, Chang YF, Shin SJ, Lein DH, Trock S, Wheeler K (1998) Clin Diagnostic Lab Immuno 5(4):550-555

26. Thorns CJ, Bell MM, Sojka MG, Nicholas RA (1996) J Clin Microbiol 34(4):792-797

27. Singh C, Agarwal GS, Rai GP, Singh L, Rao VK (2005) Electroanal 17(22):2062-2067

28. Su XL, Li Y (2005) Biosens Bioelectron 21(6):840-848

29. Kim U, Su XL, Li Y (2005) J Food Prot 68(9):1799-1803

30. Yang L, Li Y (2005) J Food Prot 68(6):1241-1245

31. Fukuda S, Tatsumi H, Igimi S, Yamamoto S (2005) Lett Appl Microbiol 41(5):379-384

32. Yoshimasu MA, Zawistowski J (2001) Appl Environ Microbiol 67 (1):459-461

33. Kim U, Su XL, Li Y (2005) J Food Prot 68(9):1799-1803

34. Bangham AD, Standish MM, Weissmann G (1965) J Mol Bio 113 (1):253-259

35. New RRC (Ed) (1990) Liposomes: a pratical approach. Oxford University Press, Oxford

36. Lurquin PF (1984) In: Greroriadis G (ed) Liposome technology: entrapment of drugs and other materials, vol II, Chap 8. CRC Press, Boca Raton

37. Ho JA, Durst RA (2000) Anal Chim Acta 414:51-60

38. Ho JA, Durst RA (2000) Anal Chim Acta 414:61-69

39. Ho JA, Wauchope RD (2002) Anal Chem 74(7):1493-1496

40. Ho JA, Hsu HW (2003) Anal Chem 75:4330-4334

41. Ho JA, Huang MR (2005) Anal Chem 77:3431-3436

42. Subramanian V, Wu LC, Huang MR, Ho JA (2006) Anal Chem 78:1115-1121

43. Ho JA, Wu LC, Huang MR, Lin YJ, Baeumner AJ, Durst RA (2007) Anal Chem 79(1):246-250

44. Ho JA, Zeng SC, Huang MR, Kuo HY (2006) Anal Chim Acta 556(1):127-132

45. Szoka F Jr, Papahadjopoulos D (1978) Proc Natl Acad Sci USA 75(9):4194-4198

46. Szoka F, Olson F, Heath T, Vail W, Mayhew E, Papahadjopoulos D (1980) Biochim Biophys Acta 601(3):559-571

47. O'Connell JP, Campbell RL, Fleming BM, Mercolino TJ, Johnson MD, McLaurin DA (1985) Clin Chem 31(9):1424-1426

48. Israelachvili JN, Mitchell DJ (1975) Biochim Biophys Acta 389 (1):13-19

49. Egawa H, Furusawa K (1999) Langmuir 15(5):1660-1666

50. Kim K, Kim C, Byun Y (2001) Langmuir 17(16):5066-5070

51. Phang T-L, Franses EI (2006) Langmuir 22(4):1609-1618

52. Solletti JM, Botreau M, Sommer F, Brunat WL, Kasas S, Duc TM, Celio MR (1996) Langmuir 12(22):5379-5386

53. Singh S, Keller DJ (1991) Biophys J 60(6):1401-1410

54. Lee KG, Pillai SR, Singh SR, Willing GA (2007) Biotechnol Bioeng. DOI 10.1002/bit.21644 